\title{
Analysis on the Incidence of the Fibularis Quartus Muscle Using Magnetic Resonance Imaging
}

\author{
Sérgio Ricardo Rios Nascimento, ${ }^{1}$ Renata Watanabe Costa, ${ }^{2}$ \\ Cristiane Regina Ruiz, ${ }^{3}$ and Nader Wafae ${ }^{4}$ \\ ${ }^{1}$ Macroscopic Anatomy and Anatomy by Radiologic Imaging, São Camilo University Center, São Paulo, SP, Brazil \\ ${ }^{2}$ Biomedicine, São Camilo University Center, São Paulo, SP, Brazil \\ ${ }^{3}$ São Camilo University Center, 04263-100 São Paulo, SP, Brazil \\ ${ }^{4}$ Paulista School of Medicine, Federal University of São Paulo, Rua Botucatu, 740, V. Clementino, 04023-062 São Paulo, SP, Brazil
}

Correspondence should be addressed to Sérgio Ricardo Rios Nascimento, riosnascimento@uol.com.br

Received 15 February 2012; Accepted 17 May 2012

Academic Editor: Nihal Apaydin

Copyright (C 2012 Sérgio Ricardo Rios Nascimento et al. This is an open access article distributed under the Creative Commons Attribution License, which permits unrestricted use, distribution, and reproduction in any medium, provided the original work is properly cited.

Objective. Quantify the presence of the fibularis quartus muscle and correlate it with the individual's sex and concomitant presence of the fibularis tertius muscle. Materials and Methods. We evaluated 211 magnetic resonance examinations (43.13\% men and $56.87 \%$ women) on the ankle and hindfoot, produced between 2009 and 2011 . Results. The fourth fibularis muscle was found to be present in $7.62 \%$ of the examinations and $75 \%$ of these also contained the fibularis tertius muscle. Conclusion. The incidence of the fourth fibularis muscle is variable; moreover, its incidence does not depend on the individual's gender or the presence of the fibularis tertius muscle.

\section{Introduction}

The fibularis quartus muscle was first described by Otto in 1816 [1] and was subsequently studied in detail by Hecker in 1923 [2]. It forms part of one of the three groups of muscle variations that occur in the ankle: the group of muscletendon variants of the fibular muscles [3]. In most cases, the presence of this muscle is asymptomatic, and it is detected by chance during the examination or surgical procedure [46]. However, in some cases, its presence is associated with certain symptoms: pain in the ankle, with or without anterior trauma; displacement, spraining, or tearing of the fibularis brevis tendon; tendon calcification; or painful hypertrophy of the retrotrochlear eminence $[4,5,7]$. The presence of the fibularis quartus muscle may simulate a longitudinal tear in the fibularis brevis tendon, but is differentiated by the presence of the muscle, when a muscle belly separated from the muscle belly of the fibularis brevis is present [8].

In most cases, the origin of the fibularis quartus muscle is posterior to the bifurcation of the belly of the fibularis muscles, or in the fibularis brevis muscle. It may also originate in the posterior dace of the fibula or in the fibularis longus muscle. Its insertion is also variable, thus explaining the variety of names that it has received: accessory fibularis muscle (insertion into the tendon of the fibularis longus, in the sole of the foot); fibulocalcaneus muscle (insertion into the retrotrochlear eminence); fibulocuboid muscle (insertion into the tuberosity of the cuboid bone, inferiorly); or fibular-fibularis longus muscle (insertion into the tendon of the fibularis longus muscle or into the inferior retinaculum of the fibularis muscles, adjacent to the retrotrochlear eminence). These last two variants are the ones with lowest incidence $[6,9,10]$. The fibularis quartus muscle acts predominantly as a pronator for the foot, as do the other fibularis muscles (longus and brevis). It has been successfully used in surgical procedures to repair and reconstruct the retinaculum of the fibularis muscles, in treating subluxation of the tendons of the fibularis muscles $[6,11]$.

Studies on the incidence of the fibularis quartus muscle have presented greatly varying results, along with greatly varying nomenclature. Studies on cadavers have presented incidence rates ranging from $13 \%$ to $23 \%$. Using ultrasound, it was found to be present in $22 \%$ of the sample. Using 
magnetic resonance imaging (MRI), it was found in $10 \%$ of the examinations [6].

Its absence in prosimians and simians and presence in humans led Hecker, in 1923 [2], to believe that this muscle was an indication of evolution or adaptation to the environment, given that its main function is to raise the lateral edge of the foot and stabilize its pronation, which are important for evolution and maintenance of bipedal posture [9]. The presence of this muscle, along with the presence of the fibularis tertius muscle, constitutes a strong indication of anatomical adaptation of the human ankle to the bipedal condition, thereby contributing towards stabilization and reinforcement of this important joint. This suggests that the symptoms associated with its presence are an indication that this adaptation has not yet completed its evolution.

Therefore, given the anatomical and clinical importance of this muscle, our aim in this study was to quantify the presence of the fibularis quartus muscle and correlate its incidence with the individual's sex and concomitant presence of the fibularis tertius muscle.

\section{Methodology}

We evaluated 211 MRI examinations on the ankle or hindfoot between 2009 and 2011. All the examinations were performed using the Signa Horizon Lx machine (General Electric Medical Systems), with a $1.5 \mathrm{~T}$ magnetic field and a quadrature coil for knees. The images analyzed were acquired using the spin echo technique with $\mathrm{T} 1$ weighting, without administering contrast medium. The images were acquired in three planes: axial-programmed parallel to the plantar fascia, from the calcaneus; sagittal_- programmed parallel to the plane of the tibia, perpendicular to the sole of the foot; coronal-programmed perpendicular to the tibial-calcaneal joint. The examinations used came from the database of the imaging diagnostics center of Hospital Santa Catarina (stored on CD-R) and were used in accordance with the authorization from the institution's ethics committee. The data were analyzed using the ONIS 2.3 Free Edition software (Digitalcore), which is available from http://www.onisviewer.com, with the aid of the hospital's radiologists. The patient's identities were kept absolutely confidential, and only the patient's gender and the side of the ankle examined were recorded.

The exclusion criteria were that examinations showing evident muscle and/or ligament injuries, or tumor lesions of any nature, and examinations performed on patients after surgical procedures, were rejected.

In assessing whether the fibularis quartus muscle was present, the following reference points were taken into consideration. In the axial plane, made with $4 \mathrm{~mm}$ of thickness and $1 \mathrm{~mm}$ of gap, observations were made starting from the slice in which the two malleoli appeared. The entire extent of the fibularis muscles and their divisions into the fibularis longus and brevis was examined, while remaining attentive for the possible presence of a third division that would suggest the presence of the fibularis quartus muscle. The slices were examined sequentially from the uppermost

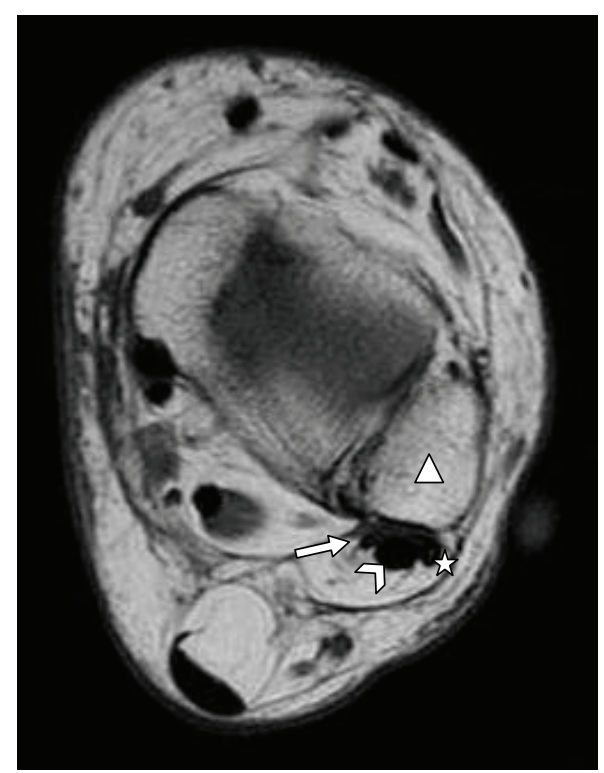

FIgURE 1: MRI, transverse T1 18/660 of left ankle. Triangle: left fibula; star: fibularis longus tendon; arrowhead: fibularis brevis tendon; arrow: fibularis quartus tendon.

slice considered to the calcaneus bone, and the insertion of this third division of the fibularis muscles was examined to determine whether the insertion was into the fibular trochlea of the calcaneus, which would characterize presence of the fibularis quartus muscle.

In the sagittal plane, made with $3 \mathrm{~mm}$ of thickness and $1 \mathrm{~mm}$ of gap, in the lateral-medial direction, the presence of a third muscle belly was observed just after the appearance of the muscle bellies of the fibularis longus and fibularis brevis. If the fibularis quartus muscle was present, it would be observed in a slice in which the fibula bone could no longer be seen, that is, close to the talus-calcaneus joint.

In the coronal plane, made with $4 \mathrm{~mm}$ of thickness and $1 \mathrm{~mm}$ of gap, slices in the region of the fibular trochlea of the calcaneus were analyzed. There, the tendons of the fibularis longus and brevis muscles were observed, along with a third tendon inserted into the fibular trochlea, thus suggesting the presence of the fibularis quartus muscle [12].

\section{Results}

Of the 211 tests evaluated, $91(43.13 \%)$ were men, 44 $(48.35 \%)$ on the right side and $47(51.65 \%)$ on the left side, and $120(56.87 \%)$ were women, $56(46.67 \%)$ on the right side $64(53.33 \%)$ on the left. Ankles rights total $100(47.39 \%)$ and 111 left ankle (52.61\%).

The fibularis quartus muscle was observed in 16 ankles (7.62\%) (Figures 1, 2, and 3), seven women (43.75\%) and 9 male $(56.25 \%)$ (Table 1$)$. Overall, it was observed the presence of muscle in 5 right ankles (31.25\%) and 11 left ankles (68.75\%).

In ankles containing the fibularis quartus muscle, 12 (75\%) also contained the fibularis tertius muscle, 6 males and 6 women ankles (Table 2). 




FIGURE 2: MRI, coronal T1 18/660 of left ankle. Star: calcaneus bone; arrow: fibularis quartus muscle.

TABLE 1: Incidence of the fibularis quartus muscle.

\begin{tabular}{lccc}
\hline & Absent & Present & Total \\
\hline Female & 113 & 7 & 120 \\
Male & 82 & 9 & 91 \\
\hline Total & 195 & 16 & 211 \\
\hline
\end{tabular}

TABLE 2: Incidence of the fibularis quartus muscle together with the fibularis tertius muscle.

\begin{tabular}{lccc}
\hline & Male & Female & Total \\
\hline Fibularis 4th & 3 & 1 & 4 \\
Fibularis 3rd and 4th & 6 & 6 & 12 \\
\hline Total & 9 & 7 & 16 \\
\hline
\end{tabular}

Based on these results was then carried out a crosssectional study, distributed in $2 \times 2$ tables (Tables 1 and 2). For the results presented in Table 1 were performed using chi-square test, $t$-student and the coefficients of Fi and Yule considering all $\alpha=0.05[13,14]$. For the results presented in Table 2 was used Fisher's test and the coefficient of Yule.

According to data obtained in this study- $\chi^{2}=1,2154$; $t=1,1004 ; \varphi=0,0759 ; q=0,278$-at the $5 \%$ level of significance, the degree of association between the presence of fibularis quartus muscle and the individual's gender is low and relatively significant, and therefore we cannot reject the hypothesis that the presence of fibularis quartus muscle is not associated with the individual's gender.

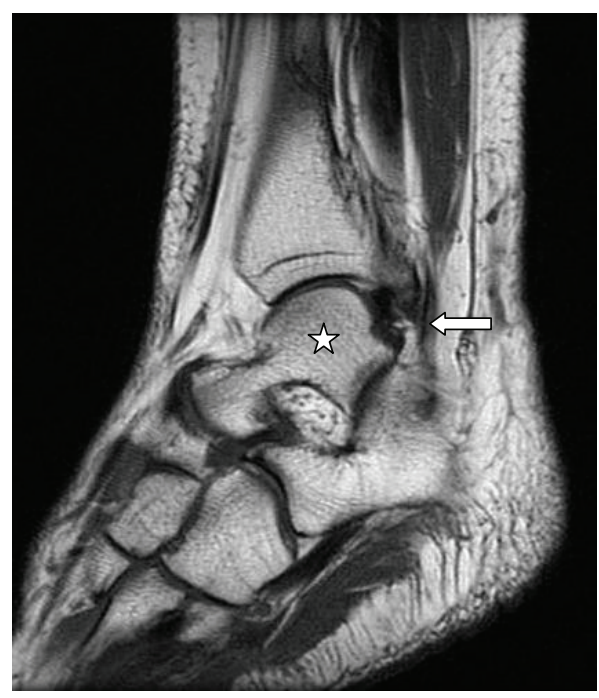

FIGURE 3: MRI, sagittal T1 23/550 of left ankle. Star: talus bone; arrow: fibularis quartus muscle.

The degree of association between the presence of fibularis quartus muscle along with the fibularis tertius muscle and gender is also low and not very significant; therefore we cannot reject the hypothesis that the individual's gender and the presence of the muscles are independent variables- $P=0,3923, q=0.5$. In cases where there is the presence of both, the ratio between the muscles presence in men and women is the same.

\section{Discussion}

Since its discovery in 1826, the fibularis quartus muscle has been objective of researches with different results, but complementaries (Tables 3 and 4).

The fibularis quartus muscle is described as a variation of the fibularis brevis muscle in the majority of the authors. Goss [10] states that the most common incidence is as fibulocalcaneus externum, originating at the back of fibula between the fibularis brevis and flexor hallucis longus with insertion on the fibular trochlea, as a statistical citing Gruber's work of dissection [15] with 3\% of incidence, although both authors do not disclose the size of the sample. Standring [16] only cited as one variation of the fibularis brevis muscle, assuming that its insertion can vary and may be in the calcaneus or in the cuboid.

Le Double [23] however, states that the fibularis quartus muscle, when fully developed, has origins in the lateral distal quarter of fibula below the fibularis brevis muscle, followed by malleolar sulcus, inserting on the base, on the proximal phalanx, or middle phalanx of fifth toe. Also according to Le Double [23] the presence of fully developed fibularis quartus muscle is quite rare and usually has its distal end withered, and this would be the reason why this muscle receives various names, according to the author who first described: Fibulocuboid muscle-Chudzinski; Fibularis accessorius muscle-Henle; Fibulocalcaneus externum muscle-Wood, Theile, and Macalister; Fibularis quartus 
TABLE 3: Quantitative research on the incidence of fibularis quartus muscle, XIX century, by the method of dissection in cadavers.

\begin{tabular}{lccccc}
\hline Author & Year & Method & $n$ & \multicolumn{2}{c}{ Incidence } \\
\hline Wood [17] & 1866 & Cadavers & 32 & 5 & $15.6 \%$ \\
Wood [18] & 1867 & Cadavers & 70 & 2 & $2.9 \%$ \\
Pozzi [19] & 1872 & Cadavers & 28 & 4 & $11.3 \%$ \\
\hline Total & & 130 & $8.5 \%$ \\
\hline
\end{tabular}

TABLE 4: Quantitative research on the incidence of fibularis quartus muscle, XX and XXI centuries, by different methods.

\begin{tabular}{|c|c|c|c|c|c|}
\hline Author & Year & Method & $n$ & Incidence & $\%$ \\
\hline Sobel et al. [20] & 1990 & Cadavers & 124 & 27 & $21.8 \%$ \\
\hline Cheung et al. [9] & 1997 & MRI & 136 & 14 & $10.3 \%$ \\
\hline Rosenberg et al. [21] & 1997 & MRI & 41 & 2 & $4.9 \%$ \\
\hline Chepuri et al. [11] & 2001 & Ultrasound/MRI & 32 & 7 & $21.9 \%$ \\
\hline Borne et al. [4] & 2002 & MRI & 63 & 7 & $11.1 \%$ \\
\hline Zammit and Singh [3] & 2003 & Cadavers & 102 & 6 & $5.9 \%$ \\
\hline Zammit and Singh [3] & 2003 & MRI & 80 & 6 & $7.5 \%$ \\
\hline Saupe et al. [5] & 2007 & MRI & 65 & 11 & $16.9 \%$ \\
\hline Tubbs et al. [22] & 2008 & Cadavers & 88 & 0 & $0.0 \%$ \\
\hline Total & & & 731 & 80 & $10.94 \%$ \\
\hline
\end{tabular}

muscle-Otto; Fibulofibularis accessorius sixth or lowerMacalister. However, Testut [24] considers the muscles fibulocuboid and fibulocalcaneus externum as a variant of fibularis quartus, and this as an incomplete variable of the fifth finger fibularis muscle. Poirier and Charpy [25] consider it as one of the many incomplete variants of the muscle known as fifth finger fibularis muscle, citing although this muscle is also present in chimpanzees and in a number of mammals.

Testut and Latarjet [26] treat any supernumerary tendon of the fibularis brevis muscle, with or without muscle belly, which has no inferior insertion at the base of the fifth finger as a rudimentary and atrophied fifth finger fibularis muscle.

Testut [24] explains that the absorption of this muscle by the others fibularis muscles-brevis and longus-would be something normal and expected due to its low incidence, investigated by Wood [17, 18] and Pozzi [19] (Table 3). Le Double [23] reinforces this theory by explaining that, unlike the upper limbs, where the muscle movements are more diverse and accurate, the muscular action of the lower limbs comes down to support body weight, balance, and gait, and therefore the lateral muscles of the lower limb, which have same function and action, are in the process of absorption by the fibularis brevis and longus muscles, larger and more constants.

Its incidence varies among studies conducted after the nineteenth century (Table 4 ), from $0 \%$ to $26 \%[3-6,9,11$, 20, 21].

The Testut [24] and Le Double [23] theory is based on the low incidence of fibularis quartus muscle, suggesting that this muscle would be absorbed by other fibularis muscles and disappear however, the incidence of fibularis quartus muscle remains, and the new analytical methods-ultrasound and MRI-showed its incidence to be increasing, although this can be explained by the increase of the studied sample and easy assessment of this muscle by the new imaging methods already mentioned.

It is useful to highlight that with the advancement of diagnostic imaging techniques, particularly magnetic resonance imaging, its study and evaluation are now simpler and more accurate, but not less intriguing. Its incidence varies according to the method used for research, with lower prevalence observed in studies using cadavers and higher incidence in studies using ultrasound exams [6]. Our results fall within the limits of what has been demonstrated until now by several studies conducted on it which suggests that after more than 180 years of its first description, its incidence is still imprecise and inconsistent.

His presence, even in a few cases, is associated with some diseases that affect the ankle joint and may also be a differential diagnosis for the hypothesis of longitudinal rupture of the fibularis brevis. However, its presence has providential value in cases where surgical repair or reconstruction of the inferior fibularis retinaculum is necessary, as described by Mick and Lynch [27] as "[. . . ] an excellent source of tissue for reconstruction of the peroneal retinaculum to prevent recurrent dislocation of the peroneal tendons."

The presence of this muscle together with the fibularis tertius muscle-already well established, with $83-95 \%$ of incidence $[6,28]$ - is contributing to the possibility of human adaptation at bipedal gait, composing a muscle tendon not only stabilizer of the ankle joint, but also contributing effectively to save energy during walking, working in eversion (fibularis quartus muscle), and dorsiflexion (fibularis tertius muscle) of the foot during the bipedal swing gait [16]. The absence of the fibularis tertius muscleconsidering an evolutionary muscle to be uniquely human and its importance in bipedal gait-is still discussed by some authors, about the lateral support to the foot during gait would be compromised $[29,30]$. 
Other authors investigated [31-38] did not mention the fibularis quartus muscle, whether as a variation or as incomplete or stunted form of another muscle. These authors cite only the presence of fibularis tertius muscle as a constant and not as an inconstant muscle.

Our results indicate that its incidence is independent of the individual's gender, being common to human beings as a whole, suggesting no relationship to gender.

Still according to the results obtained, the chance that a person who has the fibularis quartus muscle also has fibularis tertius muscle is three to one; in other words, one of three individuals that have the fibularis quartus muscle also has a fibularis tertius muscle, whether man or woman. Therefore, the presence of fibularis tertius muscle does not depend on the presence of the fibularis quartus muscle in contrast, the presence of fibularis quartus muscle increases the chances that there is a presence of fibularis tertius muscle too.

\section{Conclusions}

The fibularis quartus muscle was found in $7.62 \%$ of the population. In regarding to the side, its incidence was higher in left ankle (68.79\%) than in rights $(31.25 \%)$. In regarding to the fibularis tertius muscle, $75 \%$ of the ankles containing the fibularis quartus muscle also had this muscle. The incidence of fibularis quartus muscle, together with the fibularis tertius muscle remains inconstant, variable, and independent of the individual's gender as well as the presence of the fibularis tertius muscle. However, the chance of a person who has fibularis tertius muscle is three times bigger when the fibularis quartus muscle is present. The presence of fibularis quartus muscle is asymptomatic in most cases, but its presence is an important source of tissue for reconstruction procedures of fibular retinaculum, must be evaluated carefully, and be considered as a differential diagnosis in cases of suspect of longitudinal rupture of fibular brevis tendon.

\section{Disclosure}

This research was conducted in partnership between the São Camilo University Center and the Santa Catarina Hospital and Maternity of São Paulo, Brazil.

\section{References}

[1] R. A. Bergman, A. K. Afifi, and R. Miyauchi, "Peroneus Quartus (Otto)," Illustrated Encyclopedia of Human Anatomic Variation, 2009, http://www.anatomyatlases.org/AnatomicVariants/.

[2] P. Hecker, "Study of the peroneus of the Tarsus," Anatomical Record, vol. 26, pp. 79-82, 1923.

[3] J. Zammit and D. Singh, "The peroneus quartus muscle. Anatomy and clinical relevance," Journal of Bone and Joint Surgery B, vol. 85, no. 8, pp. 1134-1137, 2003.

[4] J. Borne, O. Fantino, J. L. Besse et al., "Aspect IRM des variantes anatomiques des muscles, tendons et ligaments de la Cheville," Journal of Radiology, vol. 83, no. 1, pp. 27-38, 2002.

[5] N. Saupe, B. Mengiardi, C. W. A. Pfirrmann, P. Vienne, B. Seifert, and M. Zanetti, "Anatomic variants associated with peroneal tendon disorders: MR imaging findings in volunteers with asymptomatic ankles," Radiology, vol. 242, no. 2, pp. 509$517,2007$.

[6] P. A. Sookur, A. M. Naraghi, R. R. Bleakney, R. Jalan, O. Chan, and L. M. White, "Accessory muscles: anatomy, symptoms, and radiologic evaluation," Radiographics, vol. 28, no. 2, pp. 481-499, 2008.

[7] X. T. Wang, Z. S. Rosenberg, M. B. Mechlin, and M. E. Schweitzer, "Normal variants and diseases of the peroneal tendons and superior peroneal retinaculum: MR imaging features," Radiographics, vol. 25, no. 3, pp. 587-602, 2005.

[8] C. A. Helms, N. M. Major, M. W. Anderson et al., Ressonância Magnética Musculoesquelética, Elsevier, Rio de Janeiro, Brazil, 2nd edition, 2010.

[9] Y. Y. Cheung, Z. S. Rosenberg, R. Ramsinghani, J. Beltran, and M. H. Jahss, "Peroneus quartus muscle: MR imaging features," Radiology, vol. 202, no. 3, pp. 745-750, 1997.

[10] C. M. Goss, Ed., Gray Anatomia, Guanabara Koogan, Rio de Janeiro, Brazil, 29th edition, 1977.

[11] N. B. Chepuri, J. A. Jacobson, D. P. Fessell, and C. W. Hayes, "Sonographic appearance of the peroneus quartus muscle: correlation with MR imaging appearance in seven patients," Radiology, vol. 218, no. 2, pp. 415-419, 2001.

[12] G. Y. El-Khoury, W. J. Montgomery, and R. A. Bergman, Sectional Anatomy by MRI and CT, Crurchil LivingstoneElsevier, Philadelphia, Pa, USA, 3rd edition, 2007.

[13] S. Vieira, Introdução a Bioestatística, Elsevier, São Paulo, Brazil, 4th edition, 2008.

[14] S. Vieira, Bioestatística: Tópicos Avançados, Elsevier, Rio de Janeiro, Brazil, 3rd edition, 2010.

[15] W. Gruber, "Ein neuer Musculus peroneo-calcaneus externus anterior," Archiv für Pathologische Anatomie und Physiologie und für Klinische Medicin, vol. 95, no. 2, pp. 177-180, 1884.

[16] S. Standring, Ed., Gray's Anatomy: The Anatomical Basis of Clinical Practice, Churchill Livingstone-Elsevier, Philadelphia, Pa, USA, 40th edition, 2008.

[17] J. Wood, "Variations in human myology observed during the winter session of 1865-66 at King's College, London," Proceedings of the Royal Society of London, vol. 16, pp. 229-244, 1866.

[18] J. Wood, "Variations in human myology observed during the winter session of 1867-68 at King's College, London," Proceedings of the Royal Society of London, vol. 16, pp. 483-525, 1868.

[19] S. Pozzi, "Sur une variété fréquente du muscle court péronier lateral chez l'homme (anomalie réversive)," Bulletins de la Société D'anthropologie de Paris, vol. 2, no. 7, pp. 155-161, 1872.

[20] M. Sobel, M. E. Levy, and W. H. O. Bohne, "Congenital variations of the peroneus quartus muscle: an anatomic study," Foot and Ankle, vol. 11, no. 2, pp. 81-89, 1990.

[21] Z. S. Rosenberg, J. Beltran, Y. Y. Cheung, E. Colon, and F. Herraiz, "MR features of longitudinal tears of the peroneus brevis tendon," American Journal of Roentgenology, vol. 168, no. 1, pp. 141-147, 1997.

[22] R. S. Tubbs, W. R. May, M. M. Shoja, L. Marios, E. G. Salter, and W. J. Oakes, "Peroneotalocalcaneus muscle," Anatomical Science International, vol. 83, no. 4, pp. 280-282, 2008.

[23] A. F. Le Double, Traite des Variations du Système Musculaire de l'homme et de leur Signification au Point de Vue de l'anthropologie Zoologique, vol. 2, Schleicher Freres, Paris, France, 1897. 
[24] L. Testut, Les Anomalies Musculaires chez l'homme Expliquées par l'anatomie Comparée leur Importance el Anthropologle, G. Masson, Paris, France, 1884.

[25] P. Poirier and A. Charpy, Traité d'Anatomie Humaine, vol. 2, no. 1, G. Masson, Paris, France, 10th edition, 1901.

[26] L. Testut and A. Latarjet, Tratado de Anatomía Humana, vol. 1, Salvat, Barcelona, Spain, 9th edition, 1951.

[27] C. A. Mick and F. Lynch, "Reconstruction of the peroneal retinaculum using the peroneus quartus. A case report," Journal of Bone and Joint Surgery A, vol. 69, no. 2, pp. 296-297, 1987.

[28] L. Marin, F. R. Barbosa, O. Andrade et al., "Estudo anatômico do músculo fibular terceiro em humanos," Arquivos Brasileiros de Cardiologia, vol. 31, no. 1, pp. 23-26, 2006.

[29] S. Das, F. H. Suhaimi, A. A. Latiff, K. P. P. Hlaing, N. A. Ghafar, and F. Othman, "Absence of the peroneus tertius muscle: cadaveric study with clinical considerations," Romanian Journal of Morphology and Embryology, vol. 50, no. 3, pp. 509$511,2008$.

[30] P. B. Iyer, "Bilateral absence of fibularis tertius: clinical implications and phylogeny," International Journal of Anatomical Variations, vol. 3, pp. 170-172, 2010.

[31] E. Gardner, D. J. Gray, and R. O'Rahilly, Anatomia: Estudo Regional do Corpo Humano, Guanabara Koogan, Rio de Janeiro, Brazil, 4th edition, 1988.

[32] A. P. Spence, Anatomia Humana Básica, Manole, São Paulo, Brazil, 4th edition, 1991.

[33] P. L. Williams, R. Warwick, M. Dyson et al., Gray Anatomia, Guanabara Koogan, Rio de Janeiro, Brazil, 37th edition, 1995.

[34] M. Latarjet and A. R. Liard, Anatomia Humana, Panamericana, São Paulo, Brazil, 2nd edition, 1996.

[35] K. L. Moore, A. F. Dalley et al., Anatomia Orientada para a Clínica, Guanabara Koogan, Rio de Janeiro, Brazil, 4th edition, 2001.

[36] K. M. van de Graaff, Anatomia Humana, Manole, São Paulo, Brazil, 6th edition, 2003.

[37] J. G. Dângelo and C. A. Fattini, Anatomia Humana Sistêmica e Segmentar, Atheneu, São Paulo, Brazil, 3rd edition, 2007.

[38] R. L. Drake, A. W. Vogl, and A. W. M. Mitchell, Gray's Anatomy for Students, Churchill Livingstone-Elsevier, Philadelphia, Pa, USA, 2nd edition, 2010. 

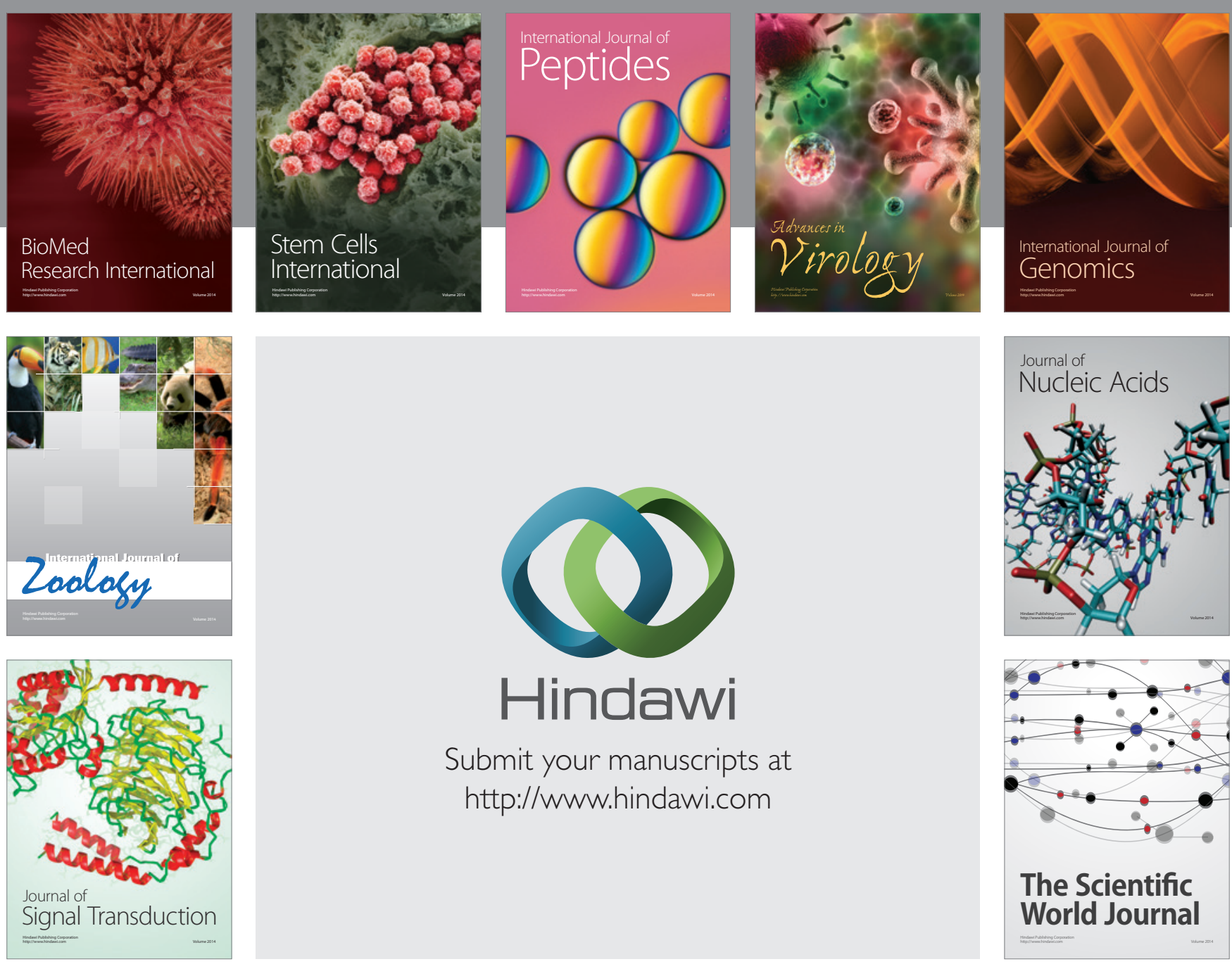

Submit your manuscripts at

http://www.hindawi.com
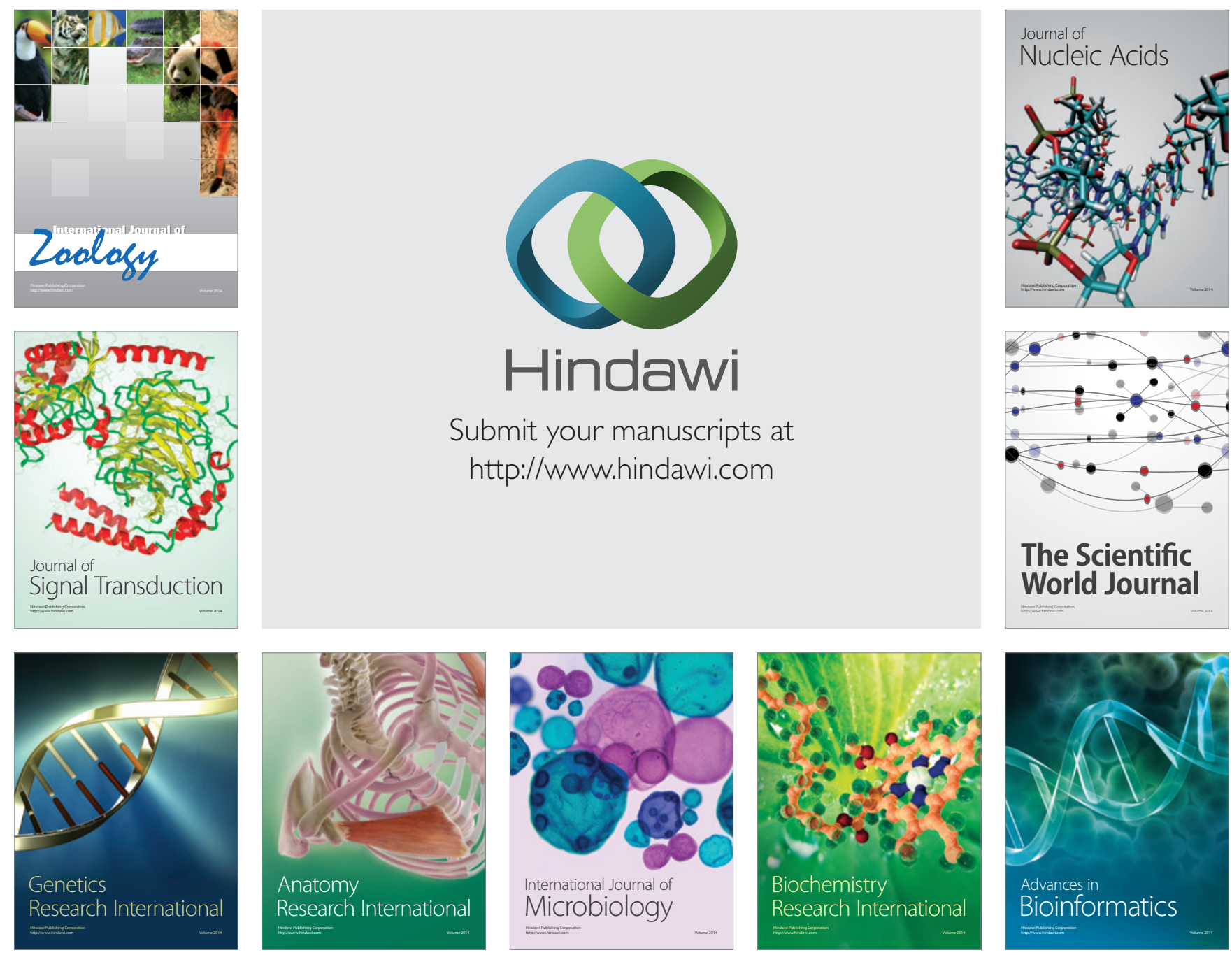

The Scientific World Journal
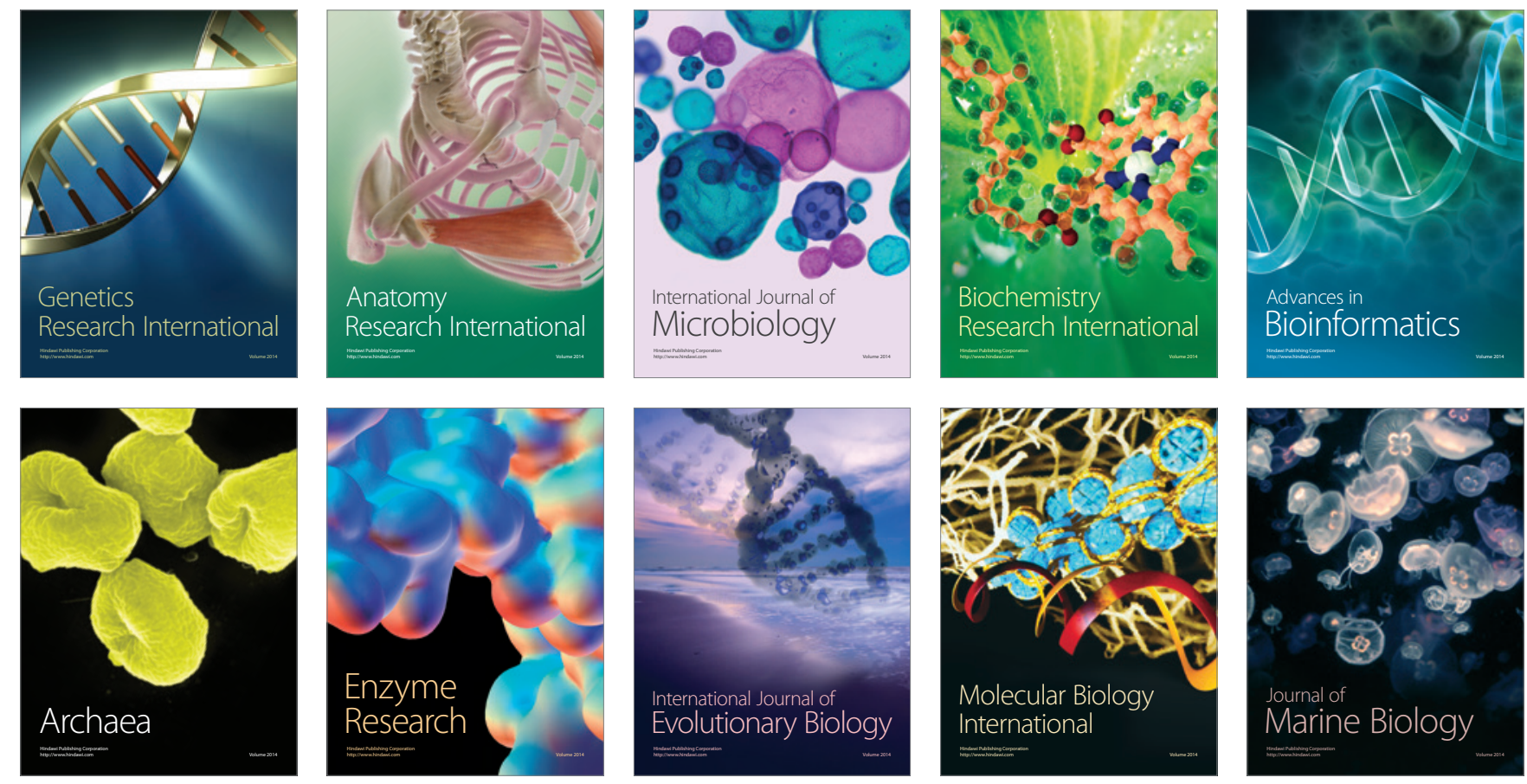